\title{
Influence of Temperature-Dependent Tensile Strength on Gun Barrel Life Prediction
}

\author{
Xuehao Geng, Kedong Zhou $(\mathbb{D}$, and Lei He \\ School of Mechanical Engineering, Nanjing University of Science and Technology, Nanjing 210094, China \\ Correspondence should be addressed to Kedong Zhou; zkd81151@126.com
}

Received 1 July 2019; Revised 13 March 2020; Accepted 18 March 2020; Published 23 April 2020

Academic Editor: Andras Szekrenyes

Copyright (c) 2020 Xuehao Geng et al. This is an open access article distributed under the Creative Commons Attribution License, which permits unrestricted use, distribution, and reproduction in any medium, provided the original work is properly cited.

\begin{abstract}
With comprehensive application of the theories of coating shear failure mechanism and fatigue cumulative damage, a life prediction method of a gun barrel is proposed based on the shear fatigue damage accumulation at the coating-substrate interface. The life of a small-caliber gun barrel is predicted by use of constant tensile strength at normal temperature and temperaturedependent tensile strength, respectively. The influence of the two kinds of tensile strength on barrel life prediction results is analyzed. Life test proves that the prediction method proposed here is credible and practical. The research results show that the reduction of interface tensile strength due to temperature rise in the firing process is an important inducement of interface damage and gun barrel failure. When the temperature-dependent tensile strength is considered in life prediction model, the prediction results are smaller than that predicted by use of constant tensile strength and well matched with the life test results. Therefore, the temperature-dependent tensile strength should be incorporated in the model of gun barrel life prediction.
\end{abstract}

\section{Introduction}

The barrel is the most important and basic part of cannon and small caliber gun. The main functions of a gun barrel are to give the projectile muzzle velocity and rotation. During the firing process, the inner bore of gun barrel suffers the scour of high-temperature and high-pressure powder gas, chemical corrosion, squeezing, and wear action of projectile movement along the barrel. Under such complicated working conditions, damage accumulation gradually takes place at inner bore after certain fired rounds, which significantly affects the ballistic performance of gun, such as firing accuracy, muzzle velocity, and keyholing projectile ratio, and then finally results in the end of barrel life. Research has indicated that heat is the primary and controlling factor among the numerous factors which cause inner bore damage [1].

Over a century, much attention has been paid on the problem of gun barrel life in ordnance industry. Various research works have been conducted by scholars on the failure mechanism, the influence factors on barrel life, and its prediction. Through comparing three likely failure mechanisms (shear failure, bending failure, and crack growth failure) of coating segment, Underwood believes that the shear stress near the coating-substrate interface is the main driving force which causes coating interface failure, and the interface shear failure is the most likely coating failure mechanism [2]. Michael and his colleagues evaluated the safe fatigue life of a large-caliber cannon tube by conducting constant amplitude testing in a laboratory setting and proposed the estimation formula of final safe fatigue life [3]. Wu studied the fatigue life of an automatic gun barrel and proposed a prediction method of gun barrel life based on the fatigue life of the coating-substrate interface [4]. Wang et al. studied the low-cycle fatigue behavior of two kinds of gun barrel steel at normal temperature by testing and found that higher toughness and hardness of steel is beneficial for improving the fatigue life of a gun barrel [5]. $\mathrm{Xu}$ et al. predicted the life of rotating barrels machine gun based on fatigue damage of the chromium-steel interface [6]. Based on calculation of the fatigue life of the chromium-steel interface, Qi et al. studied the influence of typical service conditions on the barrel life of large-caliber machine gun [7].

According to the coating-substrate interface damage accumulation method, coating desquamation is a key reason which induces the failure of a gun barrel, and the fatigue life of coating approximately equals the barrel life. The barrel life 
can be predicted by predicting fatigue life of coating based on the theory of low-cycle fatigue cumulative damage. However, in application of this method for now, the von Mises stress of the interface is often simply adopted as fatigue load and no temperature-dependent material strength is considered, which can neither reflect the mechanism of coating failure nor conform to the real high-temperature condition of inner bore during firing.

The intent of this research is to study what effect of the temperature-dependent tensile strength has on life prediction result of a gun barrel. With comprehensive application of the theories of coating shear failure mechanism and fatigue cumulative damage, a gun barrel life prediction model based on the shear fatigue damage accumulation of the coating-substrate interface is proposed. The life of a small-caliber gun barrel is predicted by use of constant tensile strength and temperature-dependent tensile strength, respectively, and the prediction results are compared and analyzed. Thereafter, life test of this small caliber gun is conducted, whose result verifies the validity of the proposed prediction model.

\section{Life Prediction Model}

2.1. Driving Force of Coating Failure. After only dozens of rounds live-firing, a mass of macroscopic cracks are found forming at the coating surface of inner bore, but coating cracking does not lead to barrel failure immediately; the following coating desquamation caused by interface failure is what controls barrel failure. Once the integrity of coating is broken, the coated barrels may erode at a faster rate than uncoated barrels [8]. However, the interface failure of coating is a long-time process; the coating can still bear thousands times of cyclic thermal shock after cracking. So it is reasonable to believe that the interface failure of coating in a gun barrel is a damage accumulation process, and the coating desquamation is fatigue behavior under the effect of cyclic thermal shock.

Figure 1 shows some key features of the shear failure mechanism for a circumferential coating segment, and an open crack is often observed adjacent to the segment, as shown at the left in the sketch. When the coating is heated by firing and is restrained from thermal expansion, transient circumferential compressive stress occurs at the closed crack side. Referring to Evans and Hutchinson's force-balance concept for misfit stress at the interface [9], once compressive stress occurs in the coating segment, shear stress will certainly occur along the base of coating segment and form a pair of balance force with the compressive stress; the force-balance concept can be expressed as

$$
\tau b L=S_{\mathrm{C}} b h,
$$

where $\tau$ is the shear stress, $S_{C}$ is the transient circumferential compressive stress, $b$ is the segment width, $L$ is the segment length, and $h$ is the coating thickness, so $b L$ is the shear area of the segment base and $b h$ is the area of the segment end which is subjected to circumferential compressive stress.

The compressive stress in coating segment is produced by thermal stress and the applied stress caused by chamber pressure, and it can be expressed as

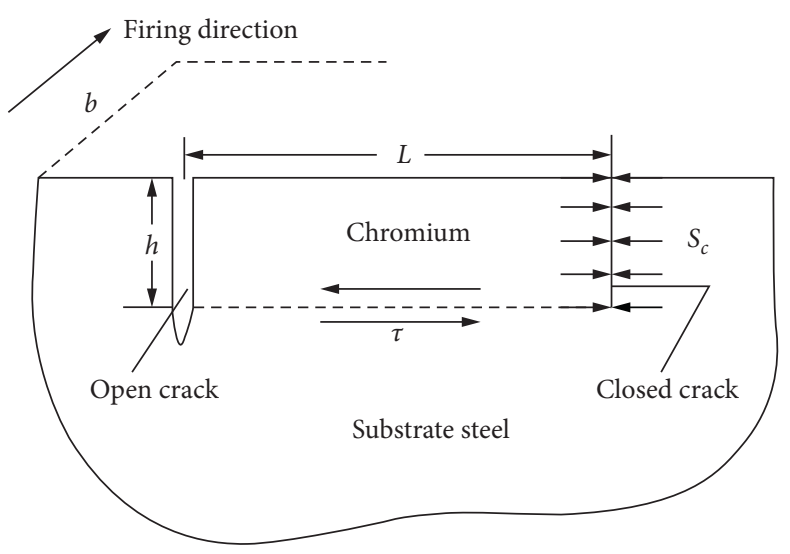

Figure 1: Shear failure model of coating in the gun barrel.

$$
S_{\mathrm{C}}=S_{\mathrm{T}}+S_{\mathrm{P}}
$$

where $S_{\mathrm{T}}$ is the thermal stress and $S_{\mathrm{P}}$ is the applied stress caused by chamber pressure.

In order to simplify the calculation, assume that $S_{\mathrm{C}}$ is a uniformly distributing load in coating depth, and the stress at half depth of coating is an approximate estimate of the mean stress from the surface to the interface. Then the transient thermal stress $S_{\mathrm{T}}$ can be written as [10]

$$
S_{\mathrm{T}}=E \alpha \frac{\left[T_{h / 2}-T_{2 h}\right]}{(1-v)}
$$

where $E$ is elastic modulus, $\alpha$ is thermal expansion coefficient, $v$ is Possion's ratio, $T_{h / 2}$ is the temperature at the half depth of coating, and $T_{2 h}$ is the temperature at double depth of coating. In addition, $S_{\mathrm{T}}$ is compressive in circumference.

The applied stress caused by chamber pressure can be obtained by the renown Lame formula based on the assumption that cracks at coating surface do not influence the distribution of applied stress; it is tensile in circumference and can be written as

$$
S_{\mathrm{P}}=\frac{p\left[1+\left(4 R^{2} /\left(2 r_{0}+h\right)^{2}\right)\right]}{\left(\left(R^{2} / r_{0}^{2}\right)-1\right)},
$$

where $p$ is the chamber pressure and $r_{0}$ and $R$ are the inner and outer radius of the gun barrel, respectively.

Considering that the stress in the gun barrel is mainly thermal stress during firing, the sign of compressive stress is set as positive, and the sign of tensile stress is set as negative here for convenience of calculation and expression; then according to equations (1) (4), the shear stress along the base of coating segment can be expressed as

$$
\tau=\frac{E \alpha\left(T_{h / 2}-T_{2 h}\right) /(1-\nu)-p\left[1+\left(4 R^{2} /\left(2 r_{0}+h\right)^{2}\right)\right] /\left(\left(R^{2} / r_{0}^{2}\right)-1\right)}{L / h} \text {. }
$$

2.2. Life Prediction Model. Since the gun barrel life is mainly controlled by the fatigue life of coating, the fatigue life of coating can be used to predict barrel life [4]. The desquamation of coating is low-cycle fatigue behavior under the 
effect of thermal-pressure coupling, so its fatigue life can be calculated by Manson-Coffin fatigue equation [11] and the corrected Morrow equation [12]. When the mean stress $\sigma_{\mathrm{m}} \neq 0$ and mean strain $\varepsilon_{\mathrm{m}} \neq 0$, the fatigue life prediction model can be expressed as

$$
\begin{aligned}
& \frac{\Delta \varepsilon}{2}=\frac{\sigma_{\mathrm{f}}^{\prime}-\sigma_{\mathrm{m}}}{E}(2 N)^{b^{\prime}}+\left(\varepsilon_{\mathrm{f}}^{\prime}-\varepsilon_{\mathrm{m}}\right)(2 N)^{a^{\prime}}, \\
& \Delta \varepsilon=\frac{\Delta \sigma}{E}+\varepsilon_{\mathrm{f}}^{\prime}\left(\frac{\Delta \sigma}{\sigma_{\mathrm{f}}^{\prime}}\right)^{1 / n^{\prime}},
\end{aligned}
$$

where $\Delta \varepsilon$ is the strain amplitude; $\Delta \sigma$ is the stress amplitude; $\sigma_{\mathrm{f}}^{\prime}$ is the fatigue strength coefficient of material, $\sigma_{\mathrm{f}}^{\prime}=\sigma_{\mathrm{b}}+350 \mathrm{MPa} ; \sigma_{\mathrm{b}}$ is the tensile strength of material; $b^{\prime}$ is the fatigue strength exponent; $a^{\prime}$ is the fatigue ductility exponent of material; $n^{\prime}$ is the cyclic strain hardening exponent; $\varepsilon_{\mathrm{f}}^{\prime}$ is the fatigue ductility coefficient of material, $\varepsilon_{\mathrm{f}}^{\prime} \approx \ln (1-\psi)^{-1} ; \psi$ is the reduction of area; and $N$ is the loading cycle, that is, the fatigue life of coating segment. Experience indicates that the parameters $a^{\prime}, b^{\prime}$, and $n^{\prime}$ relate closely to the mechanical property of material and can be obtained by following empirical formula [11]:

$$
\left\{\begin{array}{l}
a^{\prime}=-\log \left(8 \varepsilon_{\mathrm{f}}^{-0.75} \varepsilon_{\mathrm{f}}^{\prime}\right), \\
b^{\prime}=-\left[0.0792+0.179 \log \left(\frac{\sigma_{\mathrm{f}}}{\sigma_{\mathrm{b}}}\right)\right] \\
n^{\prime}=\frac{a^{\prime}}{b^{\prime}} \\
\sigma_{\mathrm{f}}^{\prime}=1.12 \sigma_{\mathrm{b}}\left(\frac{\sigma_{\mathrm{f}}}{\sigma_{\mathrm{b}}}\right)^{0.893}, \\
\varepsilon_{\mathrm{f}}^{\prime}=0.413 \varepsilon_{\mathrm{f}}\left[1-81.8\left(\frac{\sigma_{\mathrm{b}}}{E}\right)\left(\frac{\sigma_{\mathrm{f}}}{\sigma_{\mathrm{b}}}\right)^{0.179}\right]^{-1 / 3} .
\end{array}\right.
$$

The Miner linear fatigue accumulative damage theory has been widely used in engineering due to good verifiability and feasibility, so it is used here for the fatigue analysis of coating in a gun barrel $[6,7]$. Assume that the loading history consists of various levels of stress, which are $\delta_{1}, \delta_{2}$, $\ldots, \delta_{l}$. The fatigue life under each stress level is $N_{1}, N_{2}, \ldots$, $N_{l}$, respectively; the loading cycle of each stress level is $n_{1}, n_{2}$, $\ldots, n_{l}$, respectively; $l$ is the number of stress levels. Then the fatigue life of a gun barrel can be expressed as [13]

$$
N=\frac{\sum_{i=1}^{l} n_{i}}{\sum_{i=1}^{l} n_{i} / N_{i}} .
$$

\section{Temperature Field}

3.1. Heat Transfer Model. Since the temperature field of a gun barrel is an important factor affecting the stress field in the gun barrel, the tensile strength of the interface, and the life of the gun barrel, it is necessary to solve the temperature field of the gun barrel at first.

As the radial temperature gradient in the gun barrel is 1000 times more than that along the axial direction, we can ignore the axial heat transfer and simplify the barrel heat transfer model into a one-dimensional radial heat conduction model without considering the friction heat generated by projectile motion. On the basis of the above assumption, the control equation of gun barrel heat transfer can be written as follows [14]:

$$
\frac{1}{a} \frac{\partial T}{\partial t}=\frac{\partial^{2} T}{\partial r^{2}}+\frac{1}{r} \frac{\partial T}{\partial r},
$$

where $a$ is the thermal diffusivity, $t$ is time, and $r$ is the distance between a certain point in the gun barrel and the axis of symmetry.

\subsection{Definite Conditions}

Initial conditions:

$T=T_{\mathrm{a}}$ for the first round, where $T_{\mathrm{a}}$ is the ambient temperature;

$T=f(r)$ for subsequent rounds, where $f(r)$ is the temperature distribution in the gun barrel caused by fired rounds.

Boundary conditions:

Inner boundary condition:

$$
\left.\lambda_{\mathrm{c}} \frac{\partial T}{\partial r}\right|_{r=r_{0}}+\left.h_{\mathrm{g}}\left(T_{\mathrm{g}}-T\right)\right|_{r=r_{0}}=0 .
$$

Outer boundary condition:

$$
\left.\lambda_{\mathrm{s}} \frac{\partial T}{\partial r}\right|_{r=R}+\left.h_{\mathrm{a}}\left(T-T_{\mathrm{a}}\right)\right|_{r=R}=0
$$

where $\lambda_{\mathrm{c}}$ and $\lambda_{\mathrm{s}}$ are the heat conductivity coefficient of coating and substrate steel, respectively, $T_{\mathrm{g}}$ is the temperature of powder gas, $h_{\mathrm{g}}$ is the convective heat transfer coefficient between powder gas and the inner wall of the gun barrel, and $h_{\mathrm{a}}$ is the convective heat transfer coefficient between air and the outer wall of the gun barrel.

3.3. Numerical Simulation. A mass of tests have proved that the maximum chamber pressure zone is a key part concerning the barrel life [15]. The maximum chamber pressure zone suffers the maximum duration of thermal shock and works under the toughest environment during the whole firing process, so coating failure and barrel erosion always start from here. Hence, the maximum chamber pressure cross section is very representative in coating failure analysis and is taken as study object here. For the convenience of expression in following part, we define this section as Section A.

Based on FEA method, the FEM model of Section A of a small-caliber gun barrel is built and well meshed, the thickness of coating is set as $0.01 \mathrm{~mm}$, and no rifling is considered. Then the simulation program is written based on ANSYS parameter design language, and the temperature field of Section A during a whole cooling cycle is simulated numerically. The simulated firing specification is set as what 
GJB3484-98 requires, which specifically is as follows: the whole cooling cycle contains 150 rounds of shot, and these 150 rounds should be divided into single firing, burst firing, and automatic firing in certain proportion (single firing $\times 15$-five rounds burst firing $\times 3$-five rounds burst firing $\times 6$-five rounds burst firing $\times 6$-five rounds burst firing $\times 6-30$ rounds automatic firing $\times 1$; the magazine needs to be changed every 30 rounds and the standing time for changing magazine is set as 5 seconds).

\section{Interface Shear Stress}

For a cracked coating segment, the $L / h$ ratio which is related to the tensile strength of coating often has constant value range for certain coating material. It is observed that the $L / h$ ratio of electrodeposition chromium is usually about 1.5 in actual firing test [16], so 1.5 is adopted as the value of $L / h$ for chromium in calculation of interface shear stress here.

Based on the temperature field simulation results and the assumption that the interior ballistic parameters of each round are all same and independent, putting the temperature histories of $T_{h / 2}$ and $T_{2 h}$ of Section A into equation (5), then the variation of interface shear stress for Section A during the whole cooling cycle is obtained. Once the variation of interface shear stress is obtained, the variation of mean interface shear stress and interface shear stress amplitude can be also calculated easily.

Figure 2 shows the variation of mean interface shear stress $\sigma_{\mathrm{m}}$ for Section A during the whole cooling cycle. It is clear that as the fired rounds increase, the whole changing trend of mean interface shear stress increases gradually, but a small temporary decline appears during the magazinechanging period on account of temperature reduction of the gun barrel. Note that there is a small period of negative value for the mean interface shear stress in earlier stage of the cooling cycle, which means that in this period the thermal stress is lower than the applied stress caused by chamber pressure and the tensile applied stress is dominated in coating segment. However, as the fired rounds and barrel temperature increase, the thermal stress takes control gradually and the mean interface shear stress becomes positive.

Figure 3 shows the variation of interface shear stress amplitude for Section A during the whole cooling cycle. Contrary to the variation trend of mean interface shear stress, the interface shear stress amplitude declines slightly as fired rounds increase. This is because as the fired rounds increase, the thermal conductivity of barrel material and the temperature difference of powder gas and inner bore both decline on account of barrel temperature increase, which leads to the reduction of near-bore temperature amplitude for every additional round and finally causes the reduction of interface shear stress amplitude.

\section{Life Prediction and Test Verification}

5.1. Tensile Strength of Interface. Referring to [2], the actual firing experience has shown that the interface adhesive strength of properly electroplated chromium exceeds the

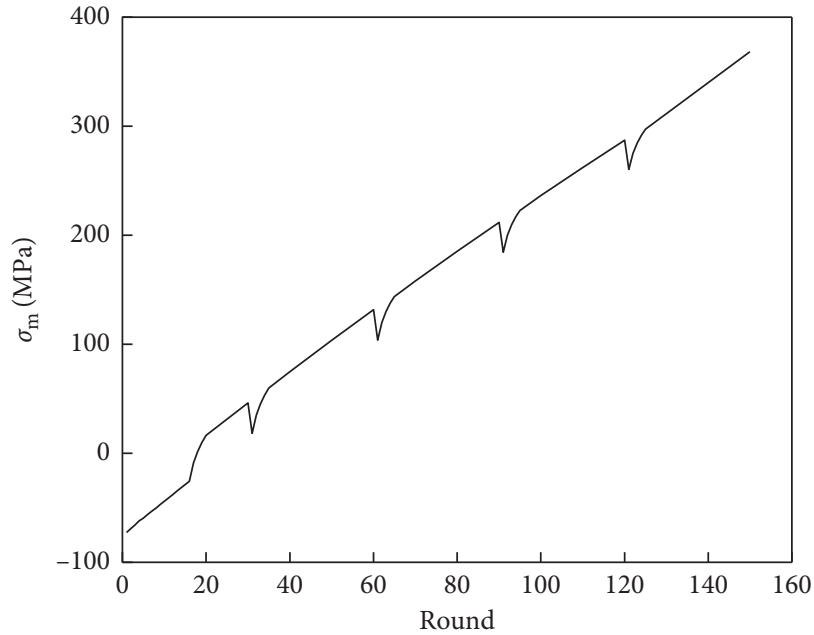

FIgURE 2: Variation of the mean stress during the whole firing process.

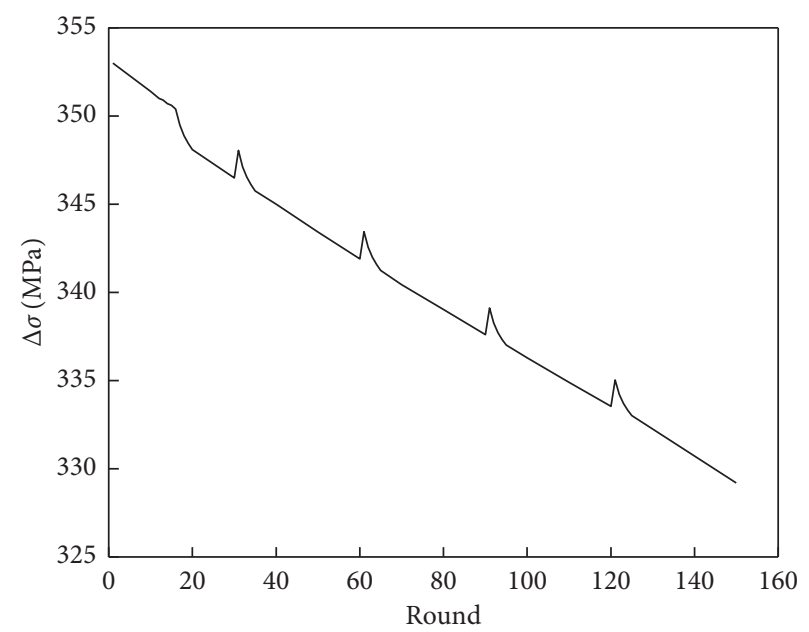

Figure 3: Variation of the interface shear stress amplitude during the whole firing process.

tensile strength of chromium, which in turn exceeds the tensile strength of substrate steel. Thus, it is believed that the tensile strength of substrate steel controls the failure of chromium segment for interface shear failure mechanism. So for the life prediction model proposed here, it is possible to regard the tensile strength of substrate steel at the interface as the interface tensile strength. In order to research the influence of temperature-dependent tensile strength on gun barrel life prediction result, constant tensile strength (Scheme 1) and temperature-dependent tensile strength (Scheme 2) are employed to predict the life of two gun barrels with different substrate steels. The two gun barrels are marked as G1 and G2, respectively, and their corresponding substrate steels are marked as M1 and M2, respectively. Tensile strengths of these two kinds of steel at different temperatures are listed in Table 1. M1 is an old type gun steel with higher tensile strength when temperature is below $400^{\circ} \mathrm{C}$, but its high-temperature strength is very poor. Contrary to this, M2 is new developed material with 
TABle 1: Tensile strength of gun barrel material at different temperature.

\begin{tabular}{lcc}
\hline \multirow{2}{*}{ Temperature $\left({ }^{\circ} \mathrm{C}\right)$} & \multicolumn{2}{c}{ Tensile strength $(\mathrm{MPa})$} \\
& $\mathrm{M} 1$ & $\mathrm{M} 2$ \\
\hline 20 & 1190 & 1150 \\
300 & 1080 & 1000 \\
350 & 1030 & 990 \\
400 & 970 & 950 \\
500 & 800 & 830 \\
600 & 550 & 660 \\
700 & 184 & 400 \\
\hline
\end{tabular}

excellent high-temperature strength property, though the tensile strength of which is little lower when temperature is below $400^{\circ} \mathrm{C}$. The higher the temperature is, the more advantage does M2 have in tensile strength. For example, at $400^{\circ} \mathrm{C}$, the tensile strength of $\mathrm{M} 2$ is still lower than $\mathrm{M} 1$, but at $500^{\circ} \mathrm{C}, 600^{\circ} \mathrm{C}$, and $700^{\circ} \mathrm{C}$, the tensile strength of $\mathrm{M} 2$ becomes $3.75 \%$ higher, $20 \%$ higher, and $117.4 \%$ higher than that of M1, respectively.

The temperature-dependent curves of tensile strength of the two materials are obtained and shown in Figure 4, by fitting the data in Table 1. The fitted temperature-dependent tensile strength expressions can be written as follows:

$$
\left\{\begin{array}{l}
\sigma_{\mathrm{b} 1}=1254.9-49.96 \cdot e^{T / 227.99}, \\
\sigma_{\mathrm{b} 2}=1202.9-57.9 \cdot e^{T / 266.8},
\end{array}\right.
$$

where $\sigma_{\mathrm{b} 1}$ and $\sigma_{\mathrm{b} 2}$ are the tensile strength of $\mathrm{M} 1$ and $\mathrm{M} 2$, respectively.

If Scheme 1 is adopted to conduct life prediction, constant tensile strength of substrate steel at room temperature $\left(20^{\circ} \mathrm{C}\right)$ will be taken as the interface tensile strength, which is $1190 \mathrm{MPa}$ for G1 and $1150 \mathrm{MPa}$ for G2. If the prediction is conducted by Scheme 2, we need to calculate the variation of interface tensile strength at first.

Assuming that the two kinds of steel have no other difference except for tensile strength, so G1 and G2 have the same temperature field distribution during firing. It is known that the temperature of near-bore region in the gun barrel varies in pulse, and hence the temperature-dependent tensile strength of the interface varies in pulse too. When the interface temperature peaks, the tensile strength of the interface touches the bottom. In consideration of the extreme working condition, the minimum interface tensile strength of every single shot is chosen for barrel life prediction in Scheme 2.

In the temperature-dependent tensile strength test, the highest test temperature is $700^{\circ} \mathrm{C}$. Though it is easy to get the tensile strength above $700^{\circ} \mathrm{C}$ through calculation by use of equation (12), the calculation results are quite low or even negative and may not be appropriate for life prediction. Because the period in which the peak interface temperature exceeds $700^{\circ} \mathrm{C}$ just takes up very little part of the whole cooling cycle, whether lower interface tensile strength is used or not in life prediction can hardly have significant influence on final prediction results, so it is assumed that the interface tensile strength would not decline any more if the interface temperature exceeds $700^{\circ} \mathrm{C}$.

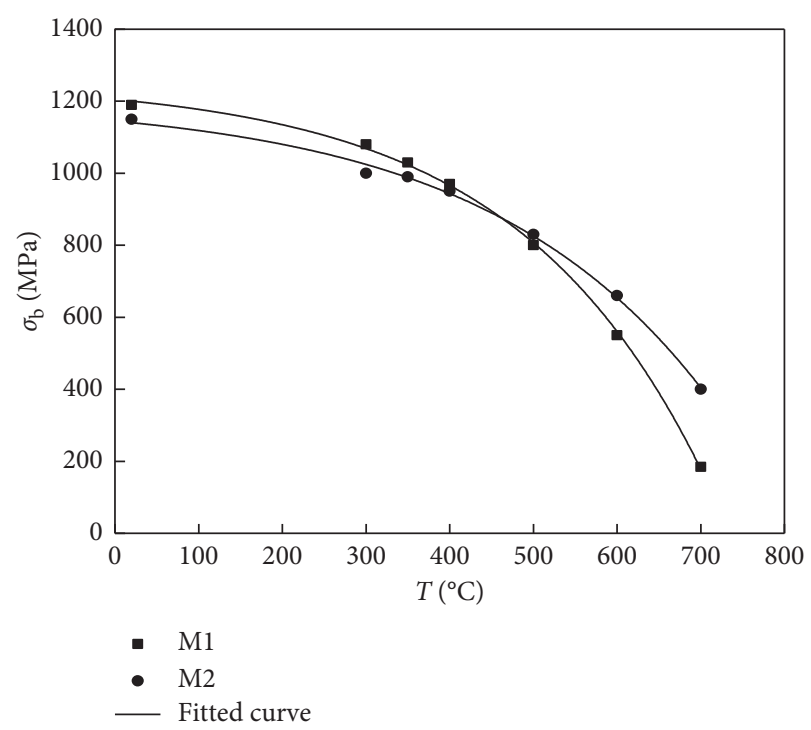

Figure 4: Fitted curves of variation of tensile strength at different temperatures.

Based on the assumptions mentioned above, putting the variation of peak interface temperature obtained from temperature field simulation into equation (12), we will get the interface tensile strength variation of G1 and G2, as shown in Figure 5. With fired rounds increase, the interface tensile strength of the two gun barrels both declines rapidly. In earlier stage of firing, G1 has higher interface tensile strength on account of low near-bore temperature. However, as the firing process proceeds, the interface tensile strength of G2 exceeds that of G1 and keeps the trend until the end of firing.

5.2. Life Prediction Results. By use of the life prediction model proposed here, the life of the gun barrel is predicted on the basis of the calculation results of mean interface shear stress, interface shear stress amplitude, and interface tensile strength. Figures 6 and 7 show the variation of predicted life under equal amplitude loading (LEAL) with fired rounds increase, for G1 and G2, respectively. The prediction results of the two schemes show highly similar variation trend if we just focus on certain single barrel; that is, the LEAL of the gun barrel declines with fired rounds increase as a whole but rises briefly when the magazine is changed. However, obvious difference appears when comparing the life prediction results of different barrels. For example, by use of Scheme 1, G1 has lager LEAL than G2 through the whole cooling cycle on account of higher interface tensile strength. While by use of Scheme 2, the LEAL of G2 is lower than G1 only in earlier stage of firing. As the firing process continues, the LEAL of G2 exceeds G1 soon and keeps advantage until the end of firing, being similar to the variation of temperature-dependent tensile strength mentioned above. The difference of prediction results obtained from different scheme indicates that the high-temperature tensile strength of the substrate is a very important influence factor which concerns barrel life, and taking the interface tensile strength as constant in gun barrel life prediction may lead to results far from actual fact. 


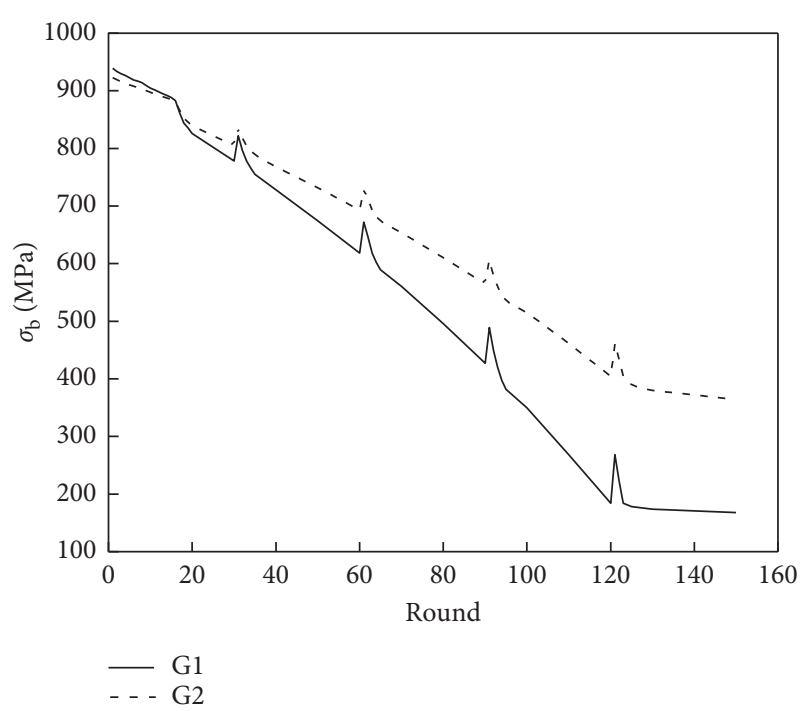

FIGURE 5: Variation of the interface tensile strength during the whole firing process.

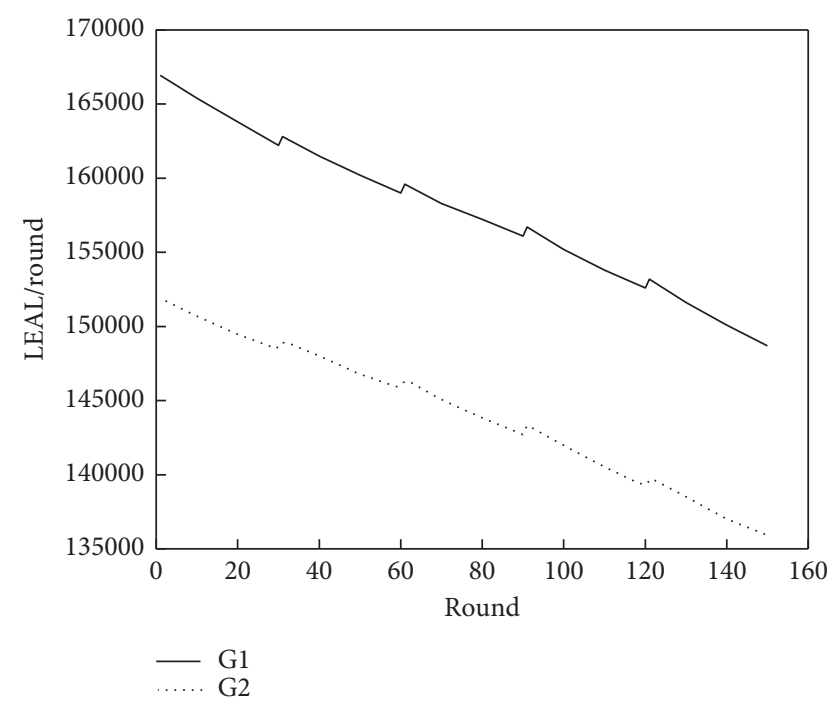

FIGURE 6: Variation of the LEAL versus fired rounds (Scheme 1).

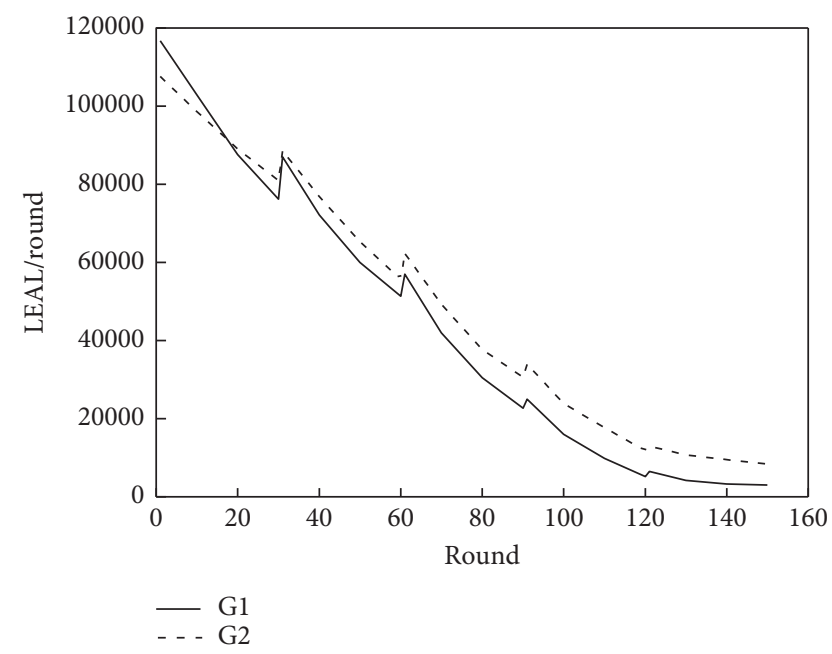

Figure 7: Variation of the LEAL versus fired rounds (Scheme 2).
The LEAL of G1 for different fired rounds and corresponding dropping rate in comparison with the first round are listed in Table 2. As fired rounds increase, the predicted LEAL of the gun barrel declines slowly by use of Scheme 1, but rapidly by use of Scheme 2. In the results of Scheme 1, the dropping rate of LEAL has never exceeded $10 \%$ before the 120 th round; even at the last round the dropping rate is only $10.9 \%$. While in the results of Scheme 2, the LEAL has already declined $56 \%$ at the 60th round in comparison with the first round. At the 120th and the last round, the dropping rate of LEAL reaches $95.5 \%$ and $97.4 \%$, respectively. For the same round, the LEAL dropping rate of Scheme 2 is always over 10 times more than that of Scheme 1.

In Scheme 1, the tensile strength of the interface is constant and the interface shear stress amplitude is declining in the firing process, so the reason that leads to the reduction of LEAL is just the rise of mean interface shear stress. While in Scheme 2, as firing proceeds, the mean interface shear stress rises gradually; meanwhile, the tensile strength of the interface declines rapidly, so the reduction of LEAL under this condition is the result of combined action of these two effects. Comparing the huge difference of the LEAL dropping rate obtained from these two schemes, it clearly shows that the rise of mean interface shear stress during firing is not the major cause that leads to the reduction of LEAL, what controls the reduction of LEAL is the reduction of interface tensile strength due to temperature rise, and we may conclude that the reduction of interface tensile strength due to temperature rise during firing is a very important inducement of coating interface failure and the end of gun barrel life. So employing constant tensile strength but not the temperature-dependent tensile strength in gun barrel life prediction means ignoring the effect of a very important inducement of barrel failure, which is not correct.

Table 3 shows the LEAL of G1 and G2 for different fired rounds, predicted by Scheme 2, and the interface temperature is the peak value obtained from temperature simulation results. At the first round, G1 has $8.6 \%$ larger LEAL than G2; at the 30th round, G2 has already come from behind and has $11.5 \%$ larger LEAL than G1; at the 60th round, the LEAL of G2 is about $12.4 \%$ larger than that of G1; when the fired rounds reach 90, 120, and 150, respectively, the LEAL of G2 is about 1.83 times, 2.27 times, and 2.77 times of the LEAL of G1, respectively. The more the accumulated fired rounds are and the higher the interface temperature is, the larger LEAL does G2 have than G1. Moreover, it is interesting to notice that great LEAL difference of these two gun barrels occurs when the interface temperature exceeds 600 . Below this temperature, the LEAL difference of these two barrels is always less than or just around $10 \%$, which indicates that the tensile strengths of substrate steel which have significant influence on the barrel life are the parts above $600^{\circ} \mathrm{C}$.

The fatigue accumulation lives of $\mathrm{G} 1$ and G2, calculated by use of equation (8), are listed in Table 4. Obviously, whether the temperature-dependent tensile strength is considered or not in the life prediction model has significant influence on prediction results. Much larger results will be obtained without consideration of the temperature- 
TABLE 2: The LEAL of G1 and corresponding drooping rate for different fired rounds.

\begin{tabular}{lcccc}
\hline Fired rounds & \multicolumn{2}{c}{ Scheme 1 } & \multicolumn{2}{c}{ Scheme 2 } \\
& LEAL/round & Dropping rate (\%) & LEAL/round & Dropping rate (\%) \\
\hline 1 & 166949 & - & 116719 & 34.7 \\
30 & 162208 & 2.8 & 51335 & 56.0 \\
60 & 159031 & 4.7 & 20696 & 82.3 \\
90 & 156095 & 6.5 & 5204 & 95.5 \\
120 & 152593 & 8.6 & 3034 & 97.4 \\
150 & 148698 & 10.9 & & \\
\hline
\end{tabular}

TABle 3: The LEAL of G1 and G2 for different fired rounds, predicted by Scheme 2.

\begin{tabular}{lccc}
\hline Fired rounds & Simulation interface temperature $\left({ }^{\circ} \mathrm{C}\right)$ & \multicolumn{2}{c}{ LEAL/round } \\
\hline 1 & & G1 & 107580 \\
30 & 420 & 116791 & 86185 \\
60 & 514 & 51335 & 57702 \\
90 & 580 & 16696 & 30625 \\
120 & 640 & 5204 & 11816 \\
150 & 700 & 3034 & 8409 \\
\hline
\end{tabular}

TABle 4: Prediction results of barrel life.

\begin{tabular}{lcc}
\hline Barrel & & Fatigue accumulation life/round \\
\hline G1 & Scheme 1 & Scheme 2 \\
G2 & 157490 & 10446 \\
\hline
\end{tabular}

dependent tensile strength. The life predicted by Scheme 1 is 15.07 times and 6.26 times of that predicted by Scheme 2 for G1 and G2, respectively. In addition, the life of G2 is about $8.6 \%$ lower than that of G1 predicted by Scheme 1, while by use of Scheme 2, the G2 life is about 2.20 times of G1 life. That is, the life prediction results are completely opposite by different prediction schemes.

5.3. Life Test Verification. In order to verify the life prediction results, life test of this small caliber gun barrel is conducted. Four guns are employed to conduct the test and marked as $1^{\#} \sim 4^{\#}$. Gun $1^{\#}$ and gun $2^{\#}$ are the test guns for $\mathrm{G} 1$, made of M1; gun $3^{\#}$ and gun $4^{\#}$ are the test guns for G2, made of M2. The test is conducted by the procedure required in GJB3484-98, and the dispersion is adopted as the failure criteria for the gun barrel, which is $R_{50}>11 \mathrm{~cm}$ specifically.

The $R_{50}$ value and accumulated fired rounds of test guns at different life stage are listed in Table 5 . The final failure life of gun $1^{\#}$ and gun $2^{\#}$ is 10299 rounds and 10634 rounds, respectively, gun $3^{\#}$ and gun $4^{\#}$ still do not fail after firing over 20000 rounds, and then the test terminates because the test objective is achieved; that is, the life of M2-made gun should reach two times at least of the life of M1-made gun. For the results predicted by Scheme 2, the error between the predicted life of G1 and test life of gun $1^{\#}$ and gun $2^{\#}$ is $1.4 \%$ and $1.8 \%$, respectively. The predicted life of G2 is 2.20 times of the life of G1, being close to the test result that the life of an M2-made gun barrel will be two times of the life of an M1-made gun barrel at least. However, as for Scheme 1, not only are the predicted lives times larger than test lives, but also the predicted life size relationship of the M1-made barrel and M2-made barrel is opposite to test results. Thus, the results predicted by Scheme 2 are well matched with test results and more accurate.

The comparison of prediction results and test results indicates that the proposed life prediction method based on the shear fatigue damage accumulation of the coatingsubstrate interface with consideration of the temperaturedependent tensile strength is credible and practical. The temperature-dependent tensile strength must be considered in the life prediction model; otherwise the prediction results would be far from the actual fact and lack of credibility. In addition, the test results and prediction results of Scheme 2 both testify that enhancing the high-temperature tensile strength of substrate steel is an effective way to extend the lifespan of a gun barrel. 
TABLE 5: Dispersion results of life test of gun barrels.

\begin{tabular}{|c|c|c|c|c|c|}
\hline \multirow{2}{*}{ Life stage } & \multicolumn{4}{|c|}{$R_{50}(\mathrm{~cm})$} & \multirow[t]{2}{*}{ Accumulated fired rounds } \\
\hline & $1^{\#}$ & $2^{\#}$ & $3^{\#}$ & $4^{\#}$ & \\
\hline Initial stage & 2.7 & 3.5 & 3.5 & 3.3 & 0 \\
\hline After the first low-temperature cycle & 4.8 & 6.8 & 8.7 & 6 & 5250 \\
\hline After the second high-temperature cycle & 8.8 & 8.2 & 6.5 & 6.8 & 8750 \\
\hline After the second low-temperature cycle & 10 & 10.2 & 8.1 & 7.8 & 10250 \\
\hline After the third normal-temperature cycle & - & - & 9.3 & 6.7 & 12390 \\
\hline After the third low-temperature cycle & - & - & 9.8 & 7.7 & 15650 \\
\hline After the fourth high-temperature cycle & - & - & 9.1 & 7.8 & 19090 \\
\hline After the fourth low-temperature cycle & - & - & 8.3 & 8.5 & 20660 \\
\hline Life end & 11.2 & 12.5 & - & - & $N^{*}$ \\
\hline
\end{tabular}

*The failure life is different for each barrel.

\section{Conclusion}

(1) The reduction of interface tensile strength due to temperature rise in the firing process is an important inducement of coating interface damage and gun barrel failure.

(2) Life test proves that the proposed life prediction method based on the fatigue damage accumulation of the coating-substrate interface with consideration of the temperature-dependent tensile strength is credible and practical.

(3) When the temperature-dependent tensile strength is considered in life prediction model, the prediction results match well with test results; otherwise, the prediction results are much larger than the test results and thus lack of credibility.

(4) If the temperature-dependent tensile strength is not incorporated into the life prediction model when predicting the barrel life, the prediction results may be opposite for the two barrels made of different substrate materials, of which one has larger tensile strength at room temperature and the other has better tensile strength at augmented temperatures.

(5) Improving the high-temperature tensile strength of substrate steel can effectively extend the lifespan of a gun barrel.

\section{Data Availability}

The data used to support the findings of this study are all included within the article.

\section{Conflicts of Interest}

The authors declare that they have no conflicts of interest.

\section{Acknowledgments}

The authors are pleased to acknowledge the help of Xu Le of Central Iron \& Steel Research Institute for providing tensile strength data of gun barrel steel and No. 208 Research Institute of China Ordnance Industries for providing life test data of gun barrel. This study is funded by the bottleneck project of the General Reserve Department of PLA (no. 30407).

\section{References}

[1] I. A. Johnston, Understanding and Predicting Gun Barrel Erosion: DSTO-TR-1757, Australia: Defence Science and Technology Organisation, Canberra, Australia, 2005.

[2] J. H. Underwood, "Thermal damage and shear failure of chromium plated coating on an A723 steel cannon tube," in Proceedings of the ASME 1999 Pressure Vessel and Piping Conference, ASME, Boston, USA, 1999.

[3] J. A. Michael, D. O. Kenneth, G. B. James et al., Fatigue Life Assessment of 155-MM M776 Cannon Tubes: ARCCB-TR99019, America: US Army Armament Research, Development and Engineering Center, Picatinny Arsenal, NJ, USA, 1999.

[4] Y. H. Wu, Inference Theory and Method of Rotating-Barrels Machine Gun Barrel Life, Nanjing University of Science and Technology, Nanjing, China, 2011.

[5] M. Wang, H. Dong, Q. Wang et al., "Low cycle fatigue behavior of high strength gun steel," Journal of University of Science and Technology Beijing, vol. 3, pp. 78-82, 2004.

[6] N. Xu, Y. H. Wu, Y. J. Wang et al., "Barrel life prediction of rotating barrels machine gun based on fatigue damage of chromium-steel interface," Acta Armamentarii, vol. 37, pp. 1926-1933, 2016.

[7] Y. H. Qi, M. H. Yang, Y. H. Shan et al., "Influence of typical service conditions on the barrel life of large-caliber machine gun," Acta Armamentarii, vol. 37, pp. 1976-1982, 2016.

[8] J. Mawella, "Protection of gun barrels from wear and erosion," in Proceedings of the TTCP Meeting, Canada: Energetic Materials and Propulsion Technology Workshop, Valcartier, Canada, 1998.

[9] A. G. Evans and J. W. Hutchinson, "The thermomechanical integrity of thin films and multilayers," Acta Metallurgica et Materialia, vol. 43, no. 7, pp. 2507-2530, 1995.

[10] J. H. Underwood, G. N. Vigilante, and C. P. Mulligan, "Review of thermo-mechanical cracking and wear mechanisms in large caliber guns," Wear, vol. 263, no. 7-12, pp. 1616-1621, 2007.

[11] S. S. Manson, "Fatigue: a complex subject-some simple approximations," Experimental Mechanics, vol. 5, no. 4, pp. 193-226, 1965.

[12] J. D. Morrow, "Laboratory simulation of low cycle fatigue behavior of the hook region of a steam turbine blade subjected to star stop cycles," in Fourth National Congress on Pressure Vessel and Piping Technology, Society of Automotive Engineers, Portland, OR, US, 1983. 
[13] S. B. Zhao, "Study on the accuracy of fatigue life prediction by the generally used damage accumulation theory," Journal of Mechanical Strength, vol. 22, pp. 206-209, 2000.

[14] G. T. Feng, Study on Flow Field with Gas Leakage and Temperature Field of Chromium-Plating Barrel, Nanjing University of Science and Technology, Nanjing, China, 2017.

[15] S. R. Zhuo, Proceedings of the Machinegun Barrel Life Prediction Technology, No. 208 Research Institute of China Ordnance Industries, Beijing, China, 1996.

[16] J. H. Underwood, A. P. Parker, G. N. Vigilante, and P. J. Cote, "Thermal damage, cracking and rapid erosion of cannon bore coatings," Journal of Pressure Vessel Technology, vol. 125, no. 3, pp. 299-304, 2003. 